\title{
Diurnal Patterns of Triglycerides, Free Fatty Acids, Blood Sugar, and Insulin during Carbohydrate- Induction in Man and Their Modification by Nocturnal Suppression of Lipolysis
}

\author{
G. SchIIERF and E. DoRow \\ From the Department of Medicine, Ludolf Krehl-Klinik, University of \\ Heidelberg, Heidelberg, Germany
}

\begin{abstract}
A B S T R A C T Previous studies have shown that carbohydrate induction of hypertriglyceridemia in normal subjects occurs at night and appears to be related to a rise of free fatty acids after diurnal feeding of high-carbohydrate formula diet. The present investigation was undertaken to observe the effect on 24-h triglyceride, free fatty acid, blood sugar, and plasma insulin profiles of inhibition of nocturnal lipolysis by glucose or nicotinic acid in normal subjects and in patients with type IV hyperlipoproteinemia.

In 10 normal subjects and 10 patients with primary type IV hyperlipoproteinemia, plasma triglyceride, free fatty acid, blood sugar, and insulin levels were followed in short intervals for $24 \mathrm{~h}$ while a 2,400 cal, $80 \%$ carbohydrate, fat-free formula diet was given in six equal portions during the day (control experiments). This procedure was repeated in the same subjects, 10 of whom ( 5 normal subjects and 5 patients) received additional feedings of glucose between 2000 and $0600 \mathrm{~h}$ while the other 10 persons ( 5 normal subjects and 5 patients) were given nicotinic acid by intravenous infusion during the same time interval. Both procedures resulted in maintained lowering of free fatty acid levels over $24 \mathrm{~h}$. Mitigation of carbohydrate-induced hypertriglyceridemia appeared to result from the additional glucose in normals and in patients. Nicotinic acid abolished the nocturnal rise of plasma triglyceride levels which in the control studies of normal subjects had resulted in approximate doubling of triglyceride levels in $24 \mathrm{~h}$.
\end{abstract}

Parts of this work were presented at the Fourth International Symposium on Drugs Affecting Lipid Metabolism, Philadelphia, Pa., 8-11 September 1971.

Received for publication 28 February 1972 and in revised form 4 August 1972.

The Journal of Clinical Investigation Volume 52 March 1973
The effectiveness of nicotinic acid in inhibiting nocturnal lipolysis and preventing carbohydrate-induction of hypertriglyceridemia might have consequences for management of endogenous hypertriglyceridemia.

\section{INTRODUCTION}

In 1961, Ahrens, Hirsch, Oette, Farquhar, and Stein (1) introduced the concept of carbohydrate-induced hypertriglyceridemia. They showed that a number of patients with primary hypertriglyceridemia responded to high carbohydrate feeding with sustained elevation of fasting plasma triglyceride levels. Subsequently, it has been shown, that carbohydrate induction may be observed in several types of primary hyperlipoproteinemias (types III, IV [2]) and that it also occurs in normals $(3,4)$, in whom it appears to be a transient phenomenon, with approximate doubling of plasma triglyceride levels within 5-7 days. With continued high carbohydrate feeding, triglycerides return to normal levels in the course of days or weeks (5).

While the phenomenon of carbohydrate induction of hypertriglyceridemia had usually been described in terms of fasting plasma triglyceride levels, we have been interested in the study of diurnal changes of plasma lipids. In 1969, we reported (6) that carbohydrate induction of hypertriglyceridemia in normal subjects occurs at night and appears to be related to a rebound rise of free fatty acids after diurnal feeding of a high carbohydrate formula diet. This biphasic response of plasma triglycerides to high carbohydrate feeding on a $24 \mathrm{~h}$ basis has since been confirmed by Barter, Carroll, and Nestel (7). 
TABLE I

Data on Patients and Control Subjects

\begin{tabular}{|c|c|c|c|c|c|c|}
\hline Patient & Sex & Age & Body wt & Height & $\begin{array}{l}\text { Weight } \\
\text { index* }\end{array}$ & Plasma TG $\ddagger$ \\
\hline \multicolumn{7}{|c|}{ Type IV patients (glucose study) } \\
\hline F. T. & $\mathbf{M}$ & 39 & 96 & 180 & 1,200 & $165 \S$ \\
\hline G. R. & $\mathbf{M}$ & 40 & 73 & 175 & 973 & 349 \\
\hline R. R. & M & 48 & 108 & 195 & 1,137 & 266 \\
\hline J. K. & $\mathbf{M}$ & 21 & 84 & 166 & 1,273 & 343 \\
\hline G. S. & $\mathbf{M}$ & 40 & 87 & 174 & 1,176 & 478 \\
\hline Mean & & 37.6 & 89.6 & 178 & 1,152 & 320 \\
\hline \multicolumn{7}{|c|}{ Normal subjects (glucose study) } \\
\hline R. L. & $\mathbf{M}$ & 30 & 61 & 174 & 824 & 86 \\
\hline K. B. & M & 25 & 65 & 178 & 833 & 56 \\
\hline G. E. & M & 25 & 66 & 172 & 916 & 76 \\
\hline T. $\mathrm{K}$. & $\mathrm{F}$ & 23 & 59 & 167 & 880 & 70 \\
\hline G. W. & M & 25 & 83 & 187 & 954 & 59 \\
\hline Mean & & 25.6 & 66.8 & 175.6 & 881 & 69 \\
\hline \multicolumn{7}{|c|}{ Type IV patients (nicotinic acid study) } \\
\hline A. Sp. & $\mathbf{M}$ & 49 & 82 & 178 & 1,051 & 285 \\
\hline W. H. & $\mathbf{M}$ & 39 & 97 & 170 & 1,386 & 1,123 \\
\hline H. H. & M & 33 & 104 & 173 & 1,425 & 1,080 \\
\hline L. W. & M & 50 & 85 & 170 & 1,214 & 400 \\
\hline A. Sc. & $\mathbf{M}$ & 65 & 75 & 165 & 1,154 & 699 \\
\hline Mean & & 47.2 & 88.6 & 171.2 & 1,246 & 717 \\
\hline \multicolumn{7}{|c|}{ Normal subjects (nicotinic acid study) } \\
\hline F. F. & $\mathbf{M}$ & 28 & 68 & 171 & 958 & 94 \\
\hline A. M. & $\mathbf{M}$ & 23 & 63 & 172 & 875 & 55 \\
\hline W. F. & M & 26 & 65 & 170 & 929 & 31 \\
\hline M. W. & M & 25 & 83 & 185 & 976 & 70 \\
\hline K. S. & M & 29 & 80 & 184 & 952 & 83 \\
\hline Mean & & 26.2 & 71.8 & $176-4$ & 938 & 67 \\
\hline
\end{tabular}

* Weight index $=$ weight $(\mathrm{kg}) /$ height $(\mathrm{cm})-100$.

$\ddagger$ Fasting values of first experiments. TG, triglyceride.

$\S$ This patient, on four previous occasions, always had TG $>200 \mathrm{mg} / 100 \mathrm{ml}$.

The present investigation was undertaken in order to study the effect on 24-h triglyceride, free fatty acid, blood sugar, and insulin profiles of inhibition of nocturnal lipolysis by glucose or nicotinic acid. Since this experimental procedure provided for quite different conditions with regard to plasma insulin levels which were high in the first and low in the second study, it should yield information not only on free fatty acid and triglyceride interrelationships on a short-term basis, but also whether substantial differences of plasma insulin levels would influence 24-h plasma triglyceride concentrations.

\section{METHODS}

Glucose study. Participants of this study were five healthy male subjects on the one hand and five patients with primary endogenous (type IV) hyperlipoproteinemia on the other. Data on sex, age, weight, and initial triglyceride levels are given in Table I.
Each subject was studied twice in randomized order. For control experiments, the subjects were admitted to the hospital in the morning, after they had been fasting for at least $12 \mathrm{~h}$. They were put to bed where they stayed for the following $24 \mathrm{~h}$. A plastic cannula was placed in a large vein of one forearm and kept open by means of a stylet. Starting at 0800 hours, these subjects were given formula diets in six divided portions of $400 \mathrm{cal}$ each. The composition of the diet was $79 \%$ of total calories from carbohydrates, $20 \%$ protein, and $1 \%$ fat (Table II). While portions of this diet were consumed at $0800,1000,1200,1400,1600$, and $1800 \mathrm{~h}$, blood samples for determination of plasma triglyceride, free fatty acid, blood sugar, and insulin concentrations were obtained hourly during the day and, after $2230 \mathrm{~h}$, every $2 \mathrm{~h}$ during the night. The blood samples were taken without a tourniquet into EDTA tubes, immediately chilled to $4^{\circ} \mathrm{C}$ until, always within a few hours, the plasma was separated by centrifugation in a cold room and immediately frozen to $-25^{\circ} \mathrm{C}$.

The second experiment, either after or preceding the control experiments by intervals of at least 5 days, were per- 
TABLE II

Composition of Formula Diet

\begin{tabular}{lcrccc}
\hline & Grams & $\begin{array}{c}\text { Carbo- } \\
\text { hydrate }\end{array}$ & Fat & Protein & Calories \\
\hline Fat-free milk solids & 320 & 166 & 3 & 115 & 1,184 \\
Maltidextrose & 270 & 262 & & & 1,080 \\
Vanilla sugar & 30 & 30 & & & 118 \\
Total of nutrients & & 458 & 3 & 115 & \\
Calories ( 2,400) & & 1,878 & 28 & 472 & \\
Percent of calories & & 79 & 1 & 20 & \\
& & & & &
\end{tabular}

formed in a similar manner. Here, in the normal subjects, only $1,800 \mathrm{cal}$ of the same formula diet were given during the day in six divided portions (300 cal each). Starting at $2000 \mathrm{~h}$ and then every $2 \mathrm{~h}$ during the night, this was followed by the oral administration of six portions of $120 \mathrm{ml}$ $50 \%$ glucose solution, amounting to $1,440 \mathrm{cal}$ at night and a total of 3,240 calories for $24 \mathrm{~h}$. The patients received identical amounts of the formula diet during the day $(2,400 \mathrm{cal})$ in the control and glucose experiments. In the latter $6 \times 120$ $\mathrm{ml} 50 \%$ glucose solution were given at night in addition, to make 3,840 cal in $24 \mathrm{~h}$.

Nicotinic acid study. Participants of this study were again five healthy young male subjects and five patients with primary (type IV) endogenous hypertriglyceridemia. The control experiments were identical to those of the glucose study, the subjects remaining in bed for $24 \mathrm{~h}$, consuming a high carbohydrate, fat-free formula diet of $2,400 \mathrm{cal}$ in six divided portions and having blood samples drawn as described. On another day, either preceding or after the control experi-

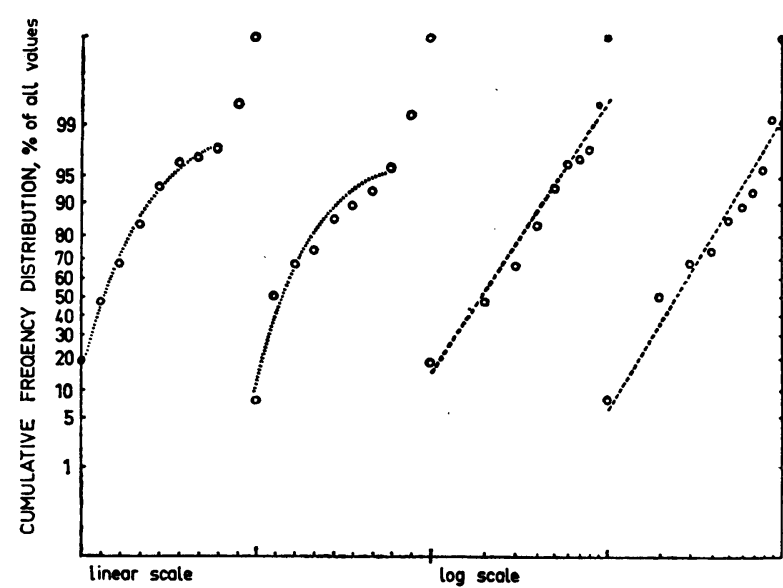

FIGURE 1 Frequency distribution of plasma triglyceride levels. More than $96 \%$ of values conform to log normal distribution.

ment, the subjects were treated in an identical manner from 0800 to $1800 \mathrm{~h}$, while, starting at $1800 \mathrm{~h}$, an intravenous infusion of nicotinic acid $(2 \mathrm{~g} / 500 \mathrm{ml} 0.9 \% \mathrm{NaCl}$ solution) was started and continued until $0600 \mathrm{~h}$ of the following day.

Laboratory methods. While blood sugar values were determined from venous blood samples on the day after each experiment by the AutoAnalyzer (Technicon Corp., Tarrytown, N. Y.), triglyceride, free fatty acid, and insulin levels for the two experiments of each patient were always determined on the same day, triglycerides by the fluorimetric method of Kessler and Lederer using the AutoAnalyzer (8),

TABLE III

Data of Statistical Analysis

\begin{tabular}{|c|c|c|c|c|c|c|c|c|c|c|}
\hline & \multicolumn{4}{|c|}{ Glucose study } & \multicolumn{4}{|c|}{ Nicotinic acid study } & \multirow[b]{2}{*}{$\alpha(0.05)$} & \multirow[b]{2}{*}{$\alpha(0.01)$} \\
\hline & BS* & Ins. & FFA & TG & BS & Ins. & FFA & TG & & \\
\hline \multicolumn{11}{|l|}{$\begin{array}{l}\text { Varianceł } \\
\text { Source }\end{array}$} \\
\hline A & 598.44 & $6,627.28$ & $2,845.91$ & 443.29 & 761.92 & $12,093.87$ & $3,695.57$ & 120.66 & & \\
\hline B & $4,522.56$ & $21,345.20$ & $18,865.02$ & 251.22 & 70.56 & 479.60 & $3,074.70$ & $2.943,06$ & & \\
\hline $\mathrm{C}$ & 147.62 & $37,558.44$ & $12,690.02$ & $381,615.00$ & 361.00 & $103,555.19$ & $29,189.72$ & 829.283 .19 & & \\
\hline $\mathrm{AB}$ & 405.24 & $4,419.49$ & $2,314.89$ & 97.37 & 17.26 & 178.17 & $2,275.40$ & 315.57 & & \\
\hline AC & 102.50 & 542.82 & 220.73 & 103.04 & 97.65 & 638.60 & 100.72 & 107.18 & & \\
\hline BC & $1,417.52$ & $17,004.16$ & $2,425.56$ & 113.42 & 14,44 & 129.96 & 5.52 & $1,132.32$ & & \\
\hline $\mathrm{ABC}$ & 38.65 & 363.06 & 79.12 & 40.56 & 21.93 & 191.77 & 47.44 & 100.83 & & \\
\hline E & 51.87 & 469.26 & 187.16 & 221.82 & 45.92 & 700.86 & 142.17 & 570.17 & & \\
\hline \multicolumn{11}{|l|}{ F-Test } \\
\hline $\mathrm{A} / \mathrm{E}$ & 11.538 & 14.128 & $15.20 \S$ & $1.99 \|$ & 16.598 & 17.268 & 25.998 & 0.21 & 1.62 & 1.97 \\
\hline $\mathrm{B} / \mathrm{AB}$ & $11.16 \|$ & $4.83 \pi$ & $8.15 \pi$ & 2.58 & 4.08 & 2.69 & 1.35 & $9.32 \|$ & 4.38 & 8.18 \\
\hline C/AC & 1.44 & 69.198 & 57.498 & $3,703.568$ & 3.70 & 162.168 & 289.818 & $7,737.298$ & 4.38 & 8.18 \\
\hline $\mathrm{AB} / \mathrm{E}$ & 7.818 & 9.428 & $12.37 \S$ & 0.44 & 0.38 & 0.25 & 16.008 & 0.55 & 1.62 & 1.97 \\
\hline $\mathrm{AC} / \mathrm{E}$ & $1.97 \|$ & 1.16 & 1.18 & 0.46 & $2.13 \|$ & 0.91 & 0.70 & 0.19 & 1.62 & 1.97 \\
\hline $\mathrm{BC} / \mathrm{ABC}$ & 36.678 & 46.838 & 30.658 & 2.78 & 0.66 & 0.68 & 0.12 & $11.23 \|$ & 4.38 & 8.18 \\
\hline $\mathrm{ABC} / \mathrm{E}$ & 0.74 & 0.77 & 0.42 & 0.18 & 0.48 & 0.27 & 0.33 & 0.18 & 1.62 & 1.97 \\
\hline
\end{tabular}

The original data from which these correlations were made have been placed in the National Auxiliary Publications Service (ID no. 02010).

* BS, blood sugar; Ins., insulin; FFA, Free fatty acids; TG, triglycerides.

Results of three way analysis of variance: A, times; B, procedures (control vs. experimental); C, diagnoses (normal vs. type IV patients); AB, interaction time/procedure; $A C$, interaction time/diagnosis; $B C$, interaction procedure/diagnosis; $A B C$, interaction time/procedure per diagnosis; $E$, error. Statistical significance:

$8 \alpha<0.001$

$\| \alpha<0.01$.

$\alpha<0.05$. 
free fatty acids after extraction according to Dole according to Lorch and Gey (9), and insulins by a modification of the radioimmunoassay of Yalow and Berson (10). All measurements were made in duplicate.

Statistical evaluation ${ }^{1}$ was performed by three-way analysis of variance after logarithmic transformation of the data. Transformation was necessary to reduce skewness to the right and achieve "normality" of distribution (Carlson and Lindstedt [11] (see Fig. 1).

The formulas used were: blood sugar, $100 \log x-150$ ( $x$ $=\mathrm{mg} / 100 \mathrm{ml}) ;$ triglycerides, $100 \log x-140(x=\mathrm{mg} / 100$ $\mathrm{ml})$; insulin, $100 \log (x+10)-100(x=\mu \mathrm{U} / \mathrm{ml})$; free fatty acids, $100 \log x-200(x=\mu \mathrm{eq} /$ liter $)$. Results of statistical analysis are given in Table III.

\section{RESULTS}

\section{Glucose study-normal subjects (Fig. 2)}

Blood sugar and insulin profiles. The blood sugar concentration spiked during the day according to meal intake and was slightly higher in the control experiments when more calories and carbohydrates were consumed during the day. At night, the curves became divergent due to the consumption of glucose in divided portions in the glucose part of the study (significant at $0.1 \%$ level).

Insulin profiles closely reflected blood sugar changes, the control curve during the day again being higher than the glucose curve. The difference between the two 24-h patterns is statistically significant at the $0.1 \%$ level.

Free fatty acid profiles. Mean fasting free fatty acid levels were slightly higher in the control experiments. Free fatty acid levels fell upon initiation of feeding and remained low during the day. In the control experiments, free fatty acid levels rose during the night. They remained low with continued glucose feeding. The difference of patterns is statistically significant at the $0.1 \%$ level.

Triglyceride profiles. Triglycerides started from similar values in control and glucose experiments. There was little change of plasma triglyceride levels during the day, the control curve being slightly lower than the glucose curve. At night, in the then fasting control group, triglycerides approximately doubled as described previously (12), while in the glucose group, the nocturnal rise appeared to be diminished. The difference between the two experiments does not reach significance.

\section{Glucose study-type IV patients (Fig. 3)}

Blood sugar and insulin profiles. During the day, blood sugar profiles were identical in the two experiments. They diverged during the night according to the patterns of food intake. The difference is statistically significant at the $0.1 \%$ level.

The insulin profiles closely reflected those of the blood sugar concentrations. Again, the difference between the

${ }^{1}$ Kindly performed by Professor $\mathrm{H}$. Immich, Abteilung für Medizinische Dokumentation und Statistik, Universität Heidelberg.

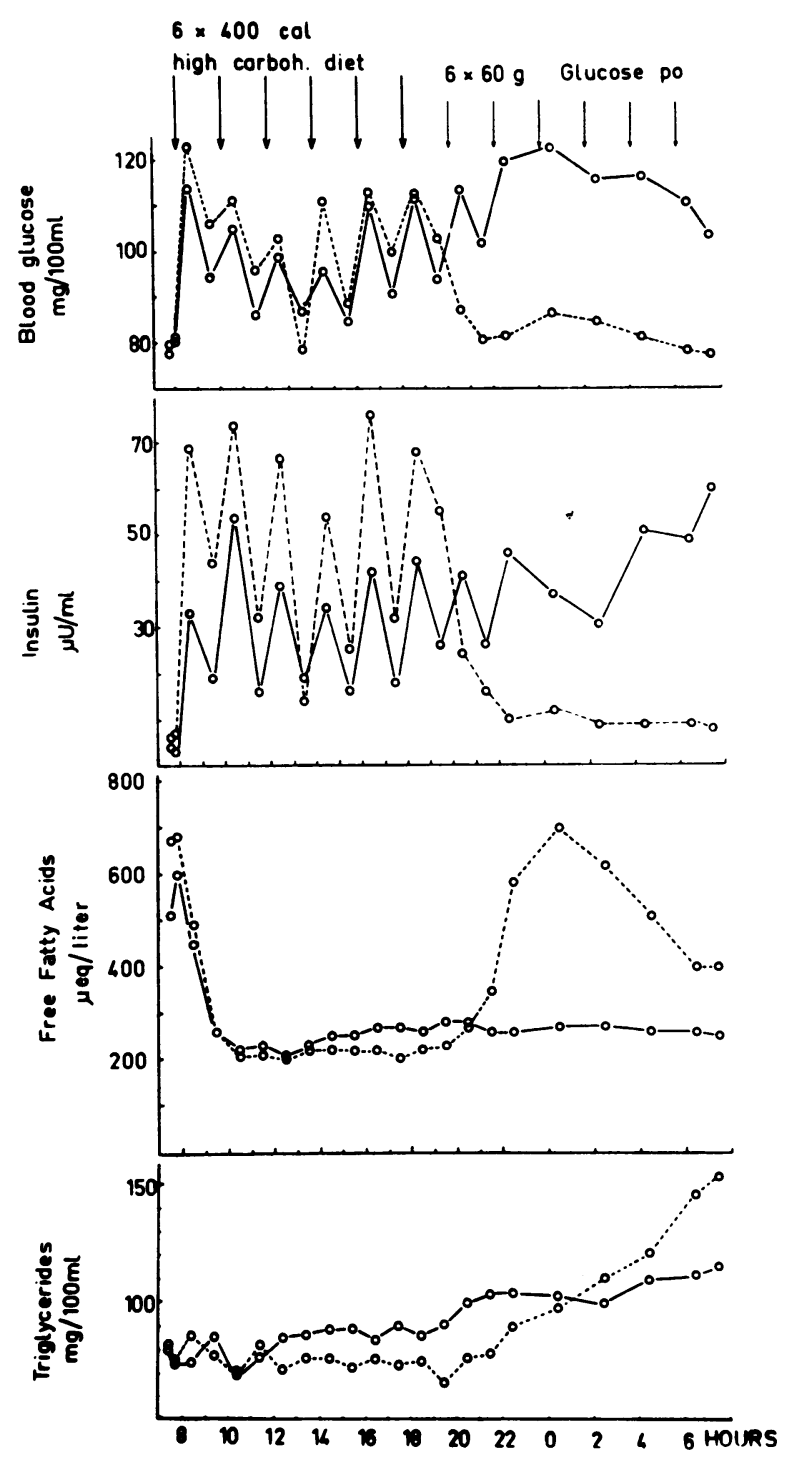

Figure 2 Mean 24-h blood sugar, insulin, free fatty acid, and triglyceride profiles in normal subjects on high carbohydrate diet without (dotted lines) and with (solid lines) additional glucose. Large arrows denote intake of formula diet, small arrows intake of glucose.

two 24-h experiments was statistically significant at the $0.1 \%$ level. Fasting as well as postprandial levels were about two times as high as in the normal subjects (difference significant at $0.1 \%$ level).

Free fatty acids. During the day free fatty acid profiles were very similar in the two experiments and slightly higher than in the normal subjects. At night, in the control experiments, there was a rebound rise of free fatty acids after the last meal, while concentrations remained low with continued glucose administration. The difference is significant at the $0.1 \%$ level. 

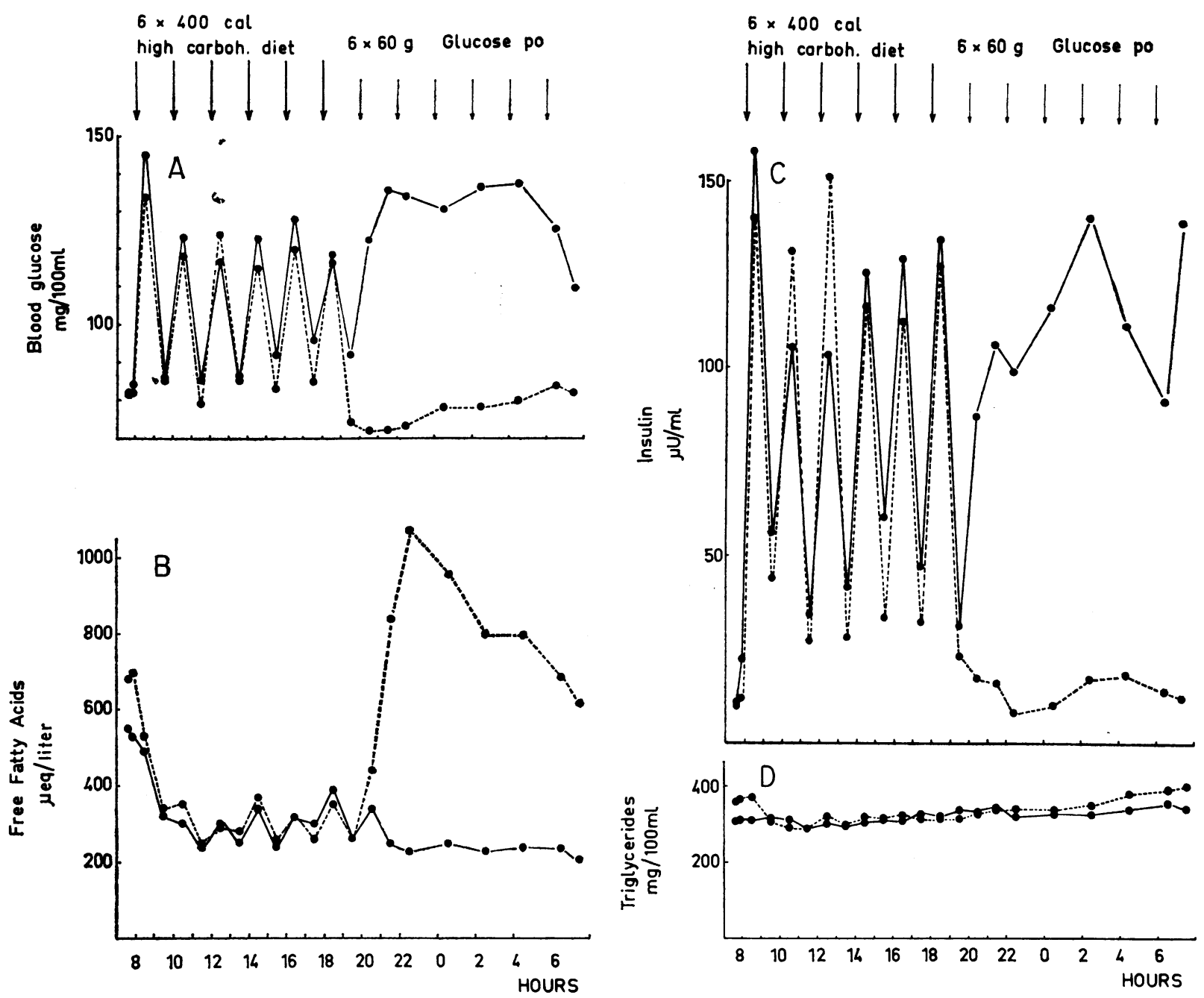

FIGURE 3 Mean 24-h blood sugar, insulin, free fatty acid, and triglyceride profiles in patients with type IV hyperlipoproteinemia on high carbohydrate diet without (dotted lines) and with (solid lines) glucose. Large arrows denote intake of formula diet, small arrows intake of glucose.

Triglycerides. Triglyceride profiles with the two experiments were identical during the day and slightly lower in the glucose experiment at night. This difference is not statistically significant.

\section{Nicotinic acid study-normal subjects (Fig. 4)}

Blood sugar and insulin profiles. The blood sugar values of this study were very similar to the control part of the glucose study in normal subjects. Insulin levels reflected changes in blood sugar concentrations. There was no difference between the control and nicotinic acid experiments.

Free fatty acids. In the control study free fatty acids behaved as described previously (12) showing the rebound rise after cessation of feeding and returning to preexperiment concentrations at the end of $24 \mathrm{~h}$. With nicotinic acid, free fatty acids remained low until the end of the infusion at $0600 \mathrm{~h}$ and rose immediately afterwards to very high levels. The difference between the two experiments is statistically significant at the $0.1 \%$ level.

Triglycerides. In the control study triglycerides rose at night, approximately doubling their concentration from 2000 to $0600 \mathrm{~h}$. With nicotinic acid there was a slight fall of triglycerides during the night hours. The last two samples, which had been taken after cessation of the nicotinic acid infusion, showed a tendency to rise. The difference between the two experiments is statistically significant at the $1 \%$ level.

Nicotinic acid study-type IV patients (Fig. 5)

Glucose and insulin profiles. Glucose profiles in the control and nicotinic acid experiments were identical and very similar to those of the control experiments in the 
glucose study with the patient group. 24-h insulin levels reflected the sugar changes. The profiles were identical in the two experiments.

Free fatty acids. Free fatty acid concentrations started from fasting levels slightly above $600 \mu \mathrm{eq} / \mathrm{liter}$, were low during the day and rose in the control experiments after cessation of feeding, which observations are similar to those in normal subjects. With nicotinic acid, free fatty acids remained low up to the end of the infusion, when they showed a steep rebound rise up to $1,900 \mu \mathrm{eq} /$ liter. The difference between the two studies is statistically significant at the $0.1 \%$ level.

Triglycerides. Triglycerides, in the control study, showed some variation during the day and rose slightly during the night, similar to their behavior in the control experiment of the glucose study. With nicotinic acid, as in normals, there was a continued fall of plasma triglyceride concentrations during the night until the end of the infusion, when two samples with rising values were noted. The difference is significant at the $1 \%$ level.

\section{DISCUSSION}

Blood sugar-insulin relationships. In 15 of the 20 experiments involving normal subjects, the time-courses of blood sugar and insulin levels during the day showed similar patterns: in spite of identical meal size, the first glucose peaks were considerably higher than the following ones, while plasma insulin levels showed an opposite behavior. Carbohydrate tolerance apparently improved during the morning and slightly deteriorated again in the afternoon, in agreement with findings of Jarrett and Keen (13) that there are significantly higher postglucose blood sugar levels in afternoon glucose tolerance tests than in tests performed in the morning. This diurnal variation of carbohydrate tolerance was less evident in the patients.

Another finding in our study, which might have been related to the obesity in the patient groups (14), was slightly higher blood sugar levels and considerably higher fasting as well as postprandial insulin levels. Therefore insulin glucose ratios were significantly higher in the patients than in the normals.

Free fatty acids. In all experiments free fatty acid levels became quite low during the day as a result of inhibition of lipolysis by elevated glucose and insulin levels (15). Lowest values in individual subjects lay around $150 \mu \mathrm{eq} /$ liter which may be the amount irreversibly bound to albumin and thus not affected by changing rates of lipolysis or free fatty acid consumption (16). Approximately $2 \mathrm{~h}$ after cessation of feeding, in the control studies, free fatty acid levels rose, rebounding considerably in some subjects, and then fell slightly again, but always remained considerably higher at night than during the day. With low glucose and insulin levels

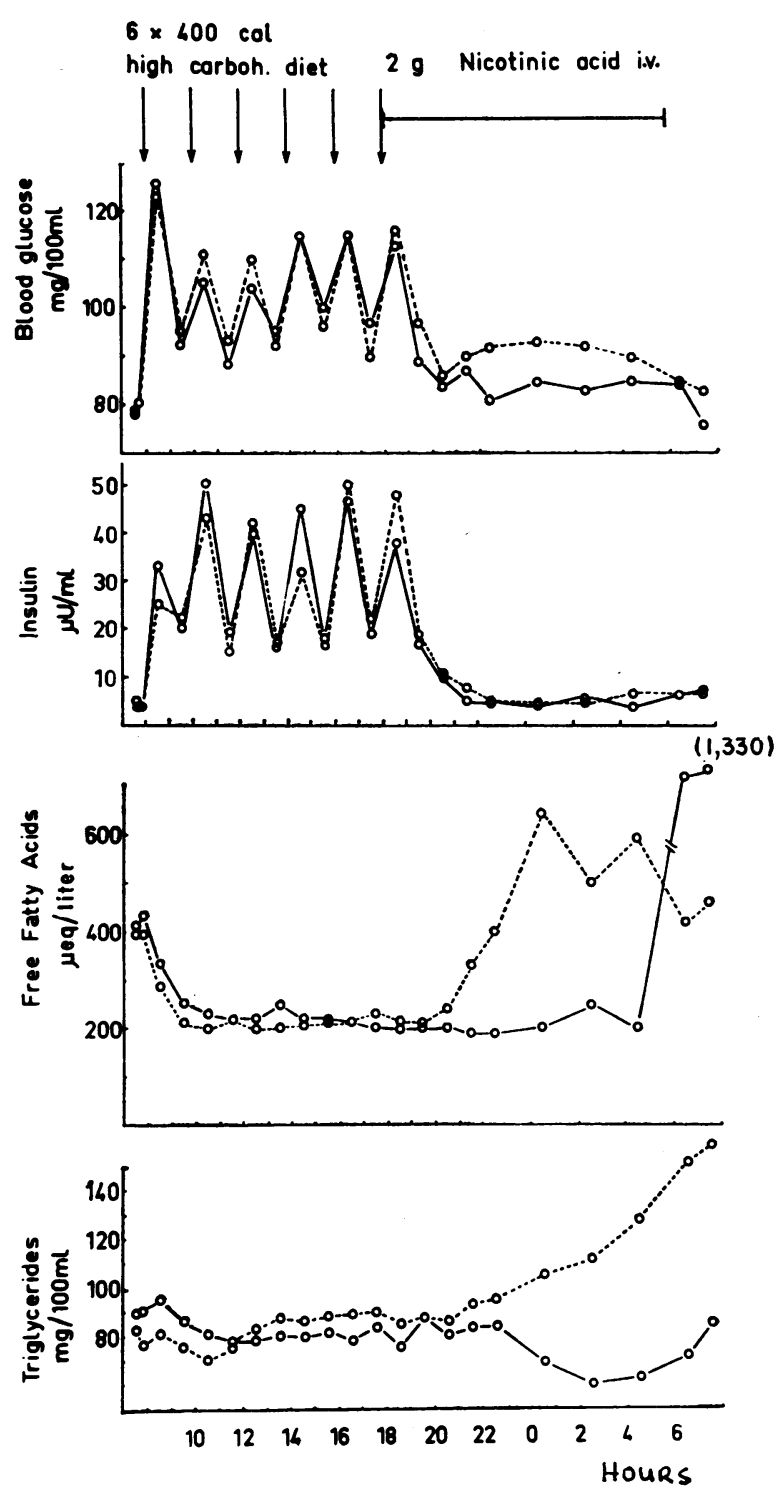

Figure 4 Mean 24-h blood sugar, insulin, free fatty acid, and triglyceride profiles in normal subjects on high carbohydrate diet without (dotted lines) and with (solid lines) noctural infusion of nicotinic acid. Arrows denote intake of formula diet.

during the night hours, lipolysis proceeds with an accelerated rate supplying fuel for many energy-consuming processes. One of the lipolytic forces at night might also be growth hormone (17) which in many subjects shows spikes at night.

In contrast to the control experiments, glucose or nicotinic acid administration at night resulted in maintained lowering of free fatty acid levels for the period of administration of the respective substances. Cessation of nicotinic acid infusion at $0600 \mathrm{~h}$ resulted in a very 

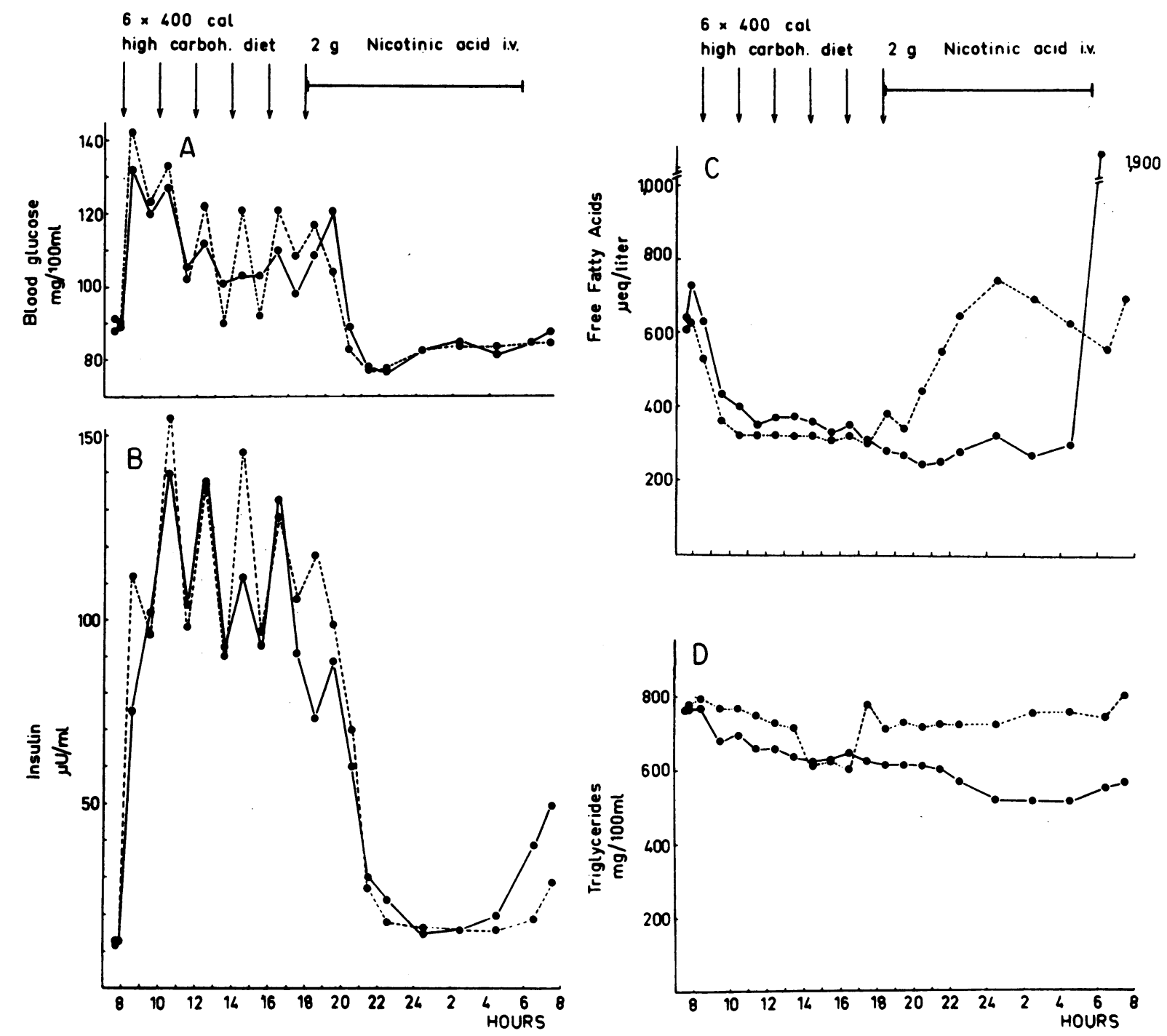

FIGURE 5 Mean 24-h blood, insulin, free fatty acid, and triglyceride profiles in patients with type IV hyperlipoproteinemia on high carbohydrate diet without (dotted lines) and with (solid lines) nocturnal infusion of nicotinic acid. Arrows denote intake of formula diet.

marked rebound rise of free fatty acids measured as early as $\mathbf{3 0} \mathrm{min}$ after the end of the infusion.

In the patients fasting free fatty acid levels were not different from those of normals, but diurnal levels were significantly higher $(0.1 \%$ level $)$ indicating less efficient suppression of lipolysis by carbohydrate feeding or decreased free fatty acid removal.

Diurnal triglycerides. In normal subjects plasma triglyceride profiles during the day with high carbohydrate feeding showed little change and were similar in all studies. At night, in the control experiments, there was a considerable rise of plasma triglyceride levels which resulted in doubling of the values from evening to morn- ing and was related to the rise of free fatty acid levels which occurred during that time (12). When free fatty acids were kept low during the night by administration of additional glucose, the rise of triglycerides appeared to be mitigated, although this impression is not substantiated by statistical analysis. It is nevertheless surprising that a combination of conditions, which are generally thought to result in increased plasma triglyceride levels, i.e. hypercaloric intake (18), glucose feeding (19), and high insulin levels (20), did not result in higher triglycerides in the glucose as compared with the control experiments. Our results are thus in agreement with those of Barter et al. (7) who, by administra- 
tion of insulin at night, observed slightly lower triglyceride levels on a sucrose diet as compared with control studies. They tend to confirm previous findings $(21,22)$ that infusion of insulin actually slightly lowers triglyceride levels during the course of several hours.

When free fatty acids were suppressed by infusion of nicotinic acid at night, plasma triglycerides stayed significantly lower for the period of the infusion and only started to rise when the infusion was terminated. Carbohydrate induction in normals was thus inhibited by nicotinic acid.

Hyperlipemic subjects. In patients of the glucose group, as in normals, the nocturnal rise of plasma triglycerides appeared to be mitigated by additional glucose administration in spite of an even higher total calorie level for $24 \mathrm{~h}(3,840 \mathrm{cal})$. If there is increased production of triglycerides by hyperinsulinemia as suggested by Reaven, Lerner, Stern, and Farquhar (20), this effect either requires more time, or removal must have been accelerated in excess of production to give a net change as observed.

In the nicotinic acid group which started from a rather high mean level of above $700 \mathrm{mg} / 100 \mathrm{ml}$, there was a slight fall of plasma triglyceride during the day in both control and nicotinic acid study and a slight rise during the night in the former. Infusion of nicotinic acid resulted in further lowering of plasma triglycerides and, at the end of the experiment, in a difference between mean values of control and drug studies of more than $200 \mathrm{mg} /$ $100 \mathrm{ml}$. The difference from the starting level was thus greater than $25 \%$. The mechanism of triglyceride lowering appears to be related to inhibition of lipolysis, although increased removal by activation of lipoprotein lipase cannot be excluded (23).

When the first and last triglyceride levels $(0800 \mathrm{~h}$ and $0730 \mathrm{~h}$ of the following day) of the control experiments in both patient groups are compared (Fig. 3 and Fig. 5), there was within $24 \mathrm{~h}$ no significant carbohydrate induction of triglyceridemia in the patients, quite contrary to the observation in normals, who, within $24 \mathrm{~h}$, doubled their triglyceride levels on the identical dietary regimen. One of several possible explanations for these findings might be that, whatever mechanisms were responsible for carbohydrate induction of triglyceridemia in the patients have already been operating on their usual diets before entrance into the study. The absence in patients with endogenous hypertriglyceridemia of the normal biphasic response of 24-h triglyceride levels to high carbohydrate feeding has been previously reported by our group (6).

There appear to emerge at least two sets of conclusions from the studies described. The first would be that, with frequent sampling of blood and lipid determinations under conditions of feeding and fasting during $24 \mathrm{~h}$, there is no evidence that elevation of plasma glucose and insulin levels, either in normals or in type IV patients, results in increased plasma triglyceride levels. The second conclusion is that dietary and drug management of hypertriglyceridemia (type IV hyperlipoproteinemia), in view of the strong correlation of free fatty acid and plasma triglyceride levels $(24,25)$, should aim at maintained lowering of the free fatty acid fraction. Although our studies were performed with diets of rather unusual and extreme makeup, a basically similar diurnal free fatty acid pattern appears to prevail with formula diets of ordinary (20\% protein, $37 \%$ fat, $43 \%$ carbohydrate) composition (26) in that highest levels are found at night. If, for drug treatment of these disorders, substances are used, the mode of action of which appears to be related to inhibition of lipolysis, it may be useful to find a way for their administration at night, when lipolysis appears to be most active.

\section{ACKNOWLEDGMENTS}

The skilled technical assistance of Mrs. M. Maser and $\mathrm{H}$. Flad is gratefully acknowledged. Preparation of formula diet was performed by Mrs. R. Geiss. Materials were kindly supplied by Dr. Wachtel, Maizena GmbH, Hamburg.

This work was supported by Deutsche Forschungsgemeinschaft.

\section{REFERENCES}

1. Ahrens, E. H., Jr., J. Hirsch, K. Oette, J. W. Farquhar, and Y. Stein. 1961. Carbohydrate-induced and fat-induced lipemia. Trans. Assoc. Am. Physicians (Phila.). $74: 134$.

2. Glueck, C. J., R. I. Levy, D. S. Fredrickson. 1960. Immunoreactive insulin, glucose tolerance, and carbohydrate inducibility in types II, III, IV and V hyperlipoproteinemia. Diabetes. 11: 739 .

3. Lees, R. S., and D. S. Fredrickson. 1965. Carbohydrateinduction of hyperlipemia in normal man. Clin. Res. 13: 327.

4. Bierman, E. L., and D. Porte, Jr. 1968. Carbohydrate intolerance and lipemia. Ann. Intern. Med. 68: 926.

5. Antonis, A., and I. Bersohn. 1961. The influence of diet on serum-triglyceride. Lancet. I : 3 .

6. Schlierf, G., and V. Stossberg. 1970. Diurnal patterns of plasma triglyceride, free fatty acid, blood sugar and insulin levels on high-fat and high-carbohydrate diets in normals and in patients with primary endogenous hyperglyceridemia. In Atherosclerosis. R. J. Jones, editor. Springer-Verlag, Berlin. 459.

7. Barter, P. J., K. F. Carroll, and P. J. Nestel. 1971. Diurnal fluctuations in triglyceride, free fatty acids, and insulin during sucrose consumption and insulin infusion in man. J. Clin. Invest. 50: 583.

8. Kessler, G., and H. Lederer. 1965. Fluorimetrische Bestimmung der Serum-Triglyzeride. Technicon-Method $\mathrm{N}-78$.

9. Lorch, E., and F. Gey. 1966. Photometric "titration" of free fatty acids with the Technicon AutoAnalyzer. Anal. Biochem. 16: 244.

10. Yalow, R. S., and S. A. Berson. 1960. Immunoassay of endogenous plasma insulin in man. J. Clin. Invest. 39 : 1157. 
11. Carlson, L. A., and S. Lindstedt. 1968. The Stockholm prospective study. 1 . The initial values for plasma lipids. Acta Med. Scand. Suppl. 493.

12. Schlierf, G., W. Reinheimer, and V. Stossberg. 1971. Diurnal patterns of plasma triglycerides and free fatty acids in normal subjects and in patients with endogenous (type IV) hyperlipoproteinemia. Nutr. Metab. 13: 80 .

13. Jarrett, R. J., and H. Keen. 1970. Further observations on the diurnal variation in oral glucose tolerance. $B r$. Med.J. 4: 334 .

14. Bagdade, J. D., E. L. Bierman, and D. Porte, Jr. 1967. Significance of basal insulin levels in the evaluation of the insulin response to glucose in diabetic and non diabetic subjects. J. Clin. Invest. 46: 1549.

15. Carlson, L. A., and P. R. Bally. 1965. Inhibition of lipid mobilization. Handb. Physiol. Sect. 5. 557.

16. Fredrickson, D. S., and R. S. Gordon, Jr. 1958. Transport of fatty acids. Physiol. Rev. 38: 585 .

17. Hansen, A. P., and K. Johansen. 1970. Diurnal patterns of blood glucose, serum free fatty acids, insulin, glucagon and growth hormone in normals and juvenile diabetics. Diabetologia. 6: 27.

18. Kinsell, L. W., and G. Schlierf. 1965. Alimentary and nonalimentary hyperglyceridemia. Ann. N. Y. Acad. Sci. $131: 603$.

19. Schlierf, G. 1971. Diätbehandlung von Hyperlipidämien. In Fettstoff wechselstörungen. G. Schettler, editor. Thieme Verlag, Stuttgart. 459.
20. Reaven, G., M. R. L. Lerner, M. P. Stern, and J. W. Farquhar. 1967. Role of insulin in endogenous hypertriglyceridemia. J. Clin. Invest. 46: 1756.

21. Jones, D. P., and R. A. Arky. 1965. Effects of insulin on triglyceride and free fatty acid metabolism in man. Metab. (Clin. Exp.). 14: 1287.

22. Schlierf, G., and L. W. Kinsell. 1965. Effect of insulin in hypertriglyceridemia. Proc. Soc. Exp. Biol. Med. 120: 272.

23. Boberg, J., L. A. Carlson, S. Fröberg, A. Olsson, L. Orö, and S. Rössner. 1971. Effects of chronic treatment with nicotinic acid on intravenous fat tolerance and postheparin lipoprotein lipase activity in man. In Metabolic Effects of Nicotinic Acid and Its Derivatives. F. Gey and L. A. Carlson, editors. Hans Huber, Bern. 465.

24. Nestel, P. J. 1967. Relationship between FFA flux and TGFA influx in plasma before and during the infusion of insulin. Metab. (Clin. Exp.). 16: 1123.

25. Sailer, S., F. Sandhofer, and Braunsteiner. 1966. Umsatzraten für freie Fettsäuren und Triglyzeride im Plasma bei essentieller Hyperlipämie. Klin. Wochenschr. 44: 1032.

26. Schlierf, G., and H. Raetzer. 1972. Diurnal patterns of blood sugar, plasma insulin, free fatty acid and triglyceride levels in normal subjects and in patients with type IV hyperlipoproteinemia and the effect of meal frequency. Nutr. Metab. 14: 113. 